\title{
Medinfo 2010: On the Way to Africa and beyond
}

\author{
L. Hanmer, B. Faye, S. Isaacs \\ Medinfo 2011 Local Organizing Committee
}

In the years leading up to Medinfo 2010, a movement of colleagues developed under the byline of 'On the way to Africa' in preparation for participating in this event. The Local Organizing Committee (LOC) took up this theme, since it reflected very clearly the long journey on many levels which had to be travelled towards Medinfo 2010. This movement also reflected the important feeling that Medinfo 2010 and other Medinfos need to become more than single events, but rather should be important milestones in multiple ongoing journeys to improve health for citizens through improved use of, and access to, health information. This theme was also taken up by the IMIA Health Information Systems Working Conference held in Franschoek just prior to Medinfo, reflecting on 31 years of experience in Hospital Information Systems since the earlier working conference on this theme held in Cape Town in 1979! For those who participated, Medinfo 2010 was a highly successful World Congress of Medical Informatics. The challenge for all of us now is to ensure that the Medinfo journey continues to Medinfo 2013 in Copenhagen and beyond.

Medinfo 2010 was both different from, and similar to, previous Medinfos. The similarities lay in the essential core of Medinfos: an excellent, wide-ranging and varied scientific programme determined very largely by the submissions received, and crafted into a coherent programme by the Scientific Program Committee (SPC), and into a comprehensive publication by the Editorial Committee (EC). The extensive Medinfo 2010 Proceedings contains the details of the 261 papers and 350 posters presented at

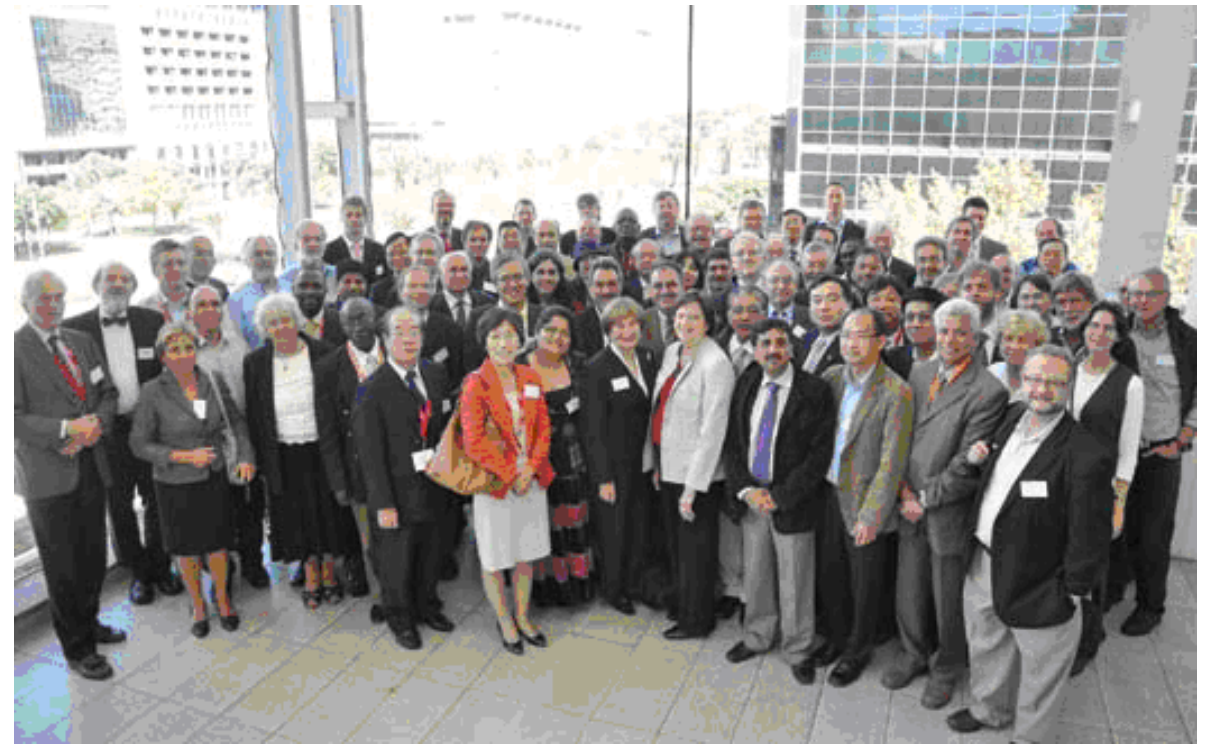

The General Assembly of the International Medical Informatics Association (IMIA) was held at the Cape Town International Convention Centre, ahead of Medinfo2010, which was opened by South Africa's Minister of Health, Dr Aaron Motsoaledi. With the beautiful city of Cape Town as backdrop, the assembly had the perfect setting for solid, yet lively and fruifful discussions.

Medinfo 2010 [1]. The IMIA Health Information Systems (HIS) Working Group of IMIA two-day conference referred to above was on the theme of "Health Information Systems - 30 Years of Evolution" [2].

The differences from previous Medinfos were both intended and unintended: The intended differences lay in the determination of the LOC (in consultation and collaboration with the other Medinfo committees) to ensure a stronger representation of issues and people from developing regions and environments than in previous Medinfos. One aspect of this difference was the concerted effort by the LOC to obtain donor support for participation by delegates from developing countries in general, and from the IMIA African region (HELINA), in particular. Another essential aspect of this focus was a mentor scheme, established and supported by the SPC with a panel of mentors, to provide for additional support in preparing submissions for any authors who wished to make use of this opportunity. At least partly as a result of these efforts, we identified 24 papers including African authors and/ or on topics related to Africa in Medinfo 2010, compared with three papers including African authors at the previous Medinfo. More than 60 delegates from developing countries were fully or partially supported to participate in the conference through various donations solicited for this purpose. These included both presenters and identified health service managers who could influence the success of health informatics applications in their environments. 
Unintended differences from previous Medinfos were mainly due to the worldwide economic crisis which occurred when the LOC was in the throes of sourcing the sponsorship essential to the financial success of the Congress. Sponsorship proved very hard to come by, resulting in a very limited budget and very challenging cash-flow issues at times, which made it impossible to conduct business as usual. Completion of the Medinfo preparation would not have been possible without the willingness of the SPC in particular to change its mode of operation to achieve considerable savings on the projected budget, without compromising the quality of the scientific programme. Support from the IMIA board and changes to marketing plans were other necessary components of managing very limited resources. Anecdotal evidence from participants and potential participants was that the crisis also impacted negatively on their personal ability to obtain funding from other sources necessary to get to Cape Town for Medinfo 2010.

The experience at Medinfo 2010 was that there was limited demand for the printed version of the Proceedings,

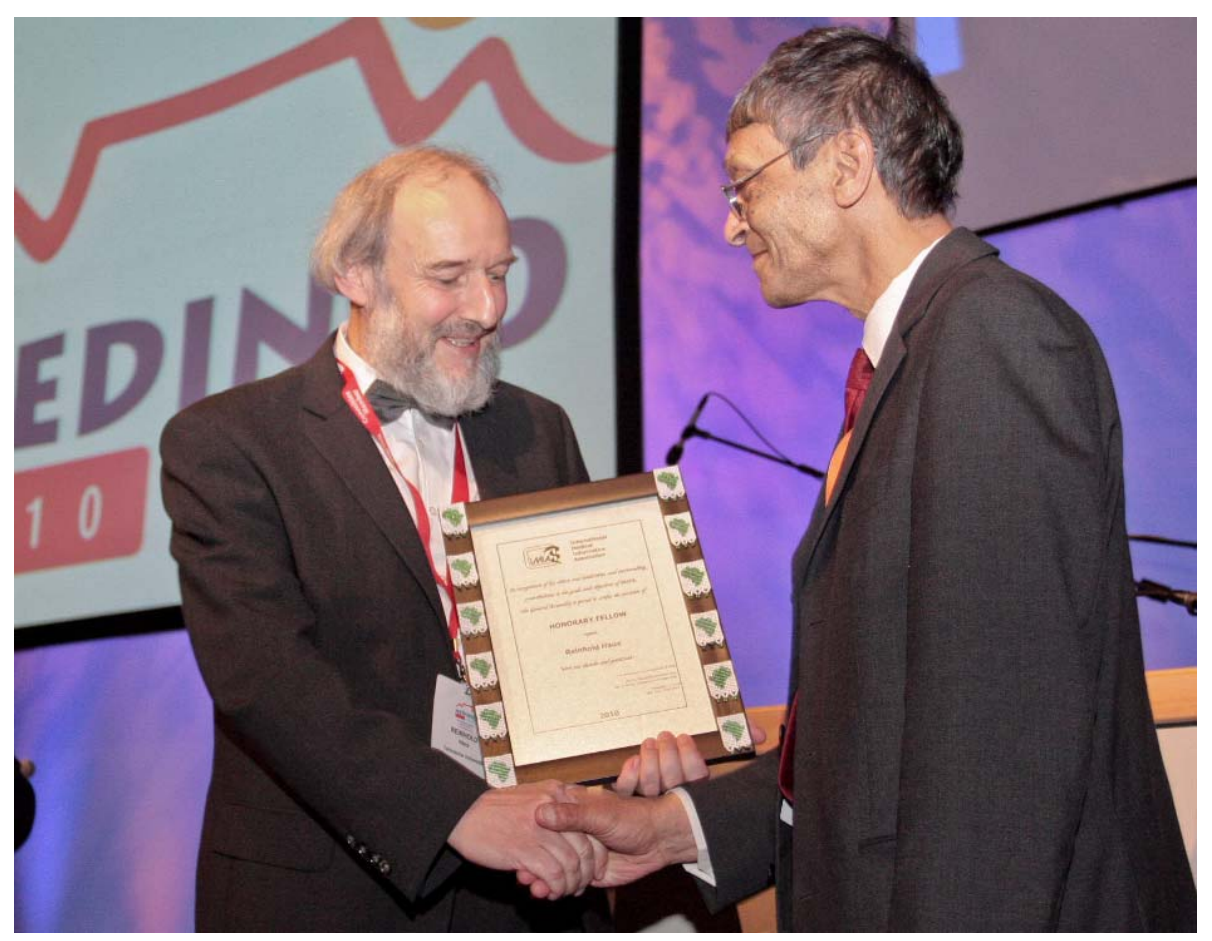

Sedick Isaacs received his Honorary Fellowship from IMIA President, Prof Reinhlold Haux.

suggesting that for future Medinfos, it will be more cost-effective to concentrate on providing electronic access to them, with printing on demand only for

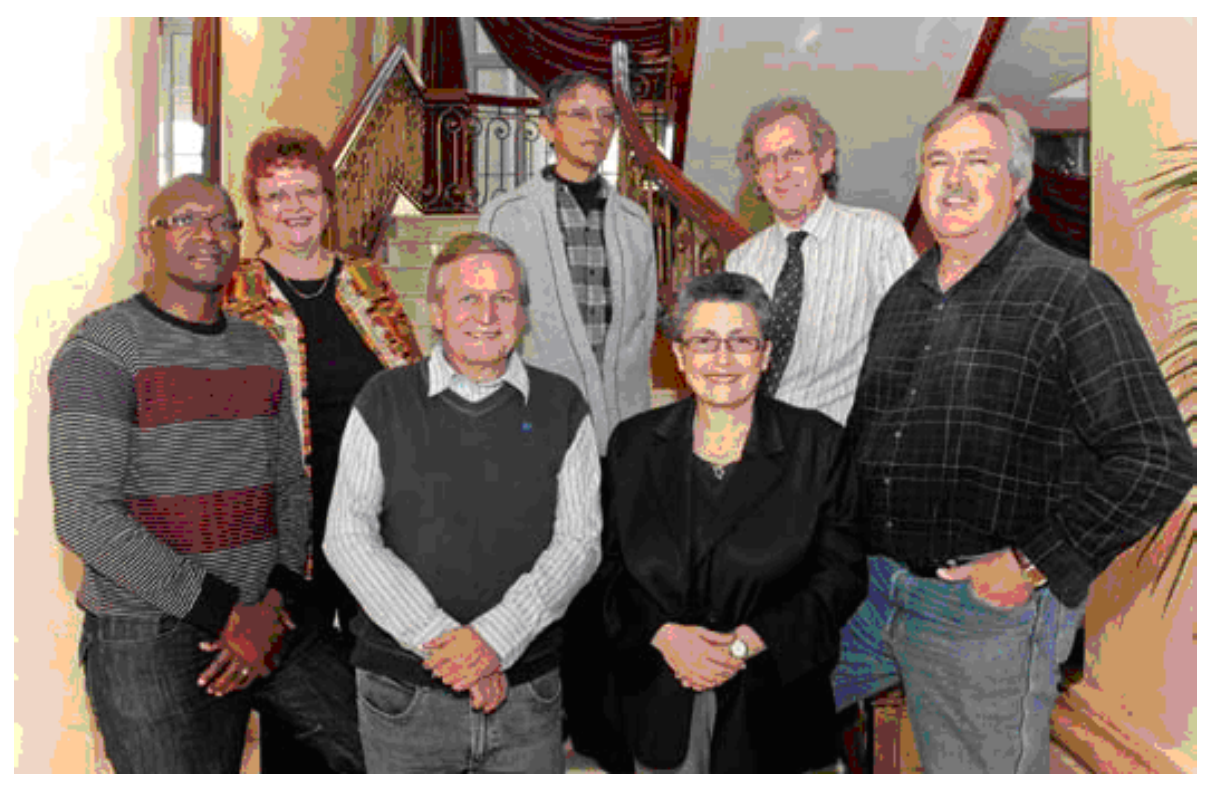

The backroom boys and gals - the local organising committee, from left Vuma Magaqa, Brenda Faye, Roy Alger, Sedick Isaacs, Lyn Hanmer, Chris Cockett and Johann Odendaal those who really need it. The IMIA electronic services are being extended, which should contribute to more effective use of electronic media for support of future Medinfos.

Ultimately, the success of Medinfos depends on the commitment and dedication of the people involved in the process. For those who participated in Medinfo 2010, the members of the junior choir who performed at the opening ceremony (and those who prepared them) were very special people! The keynote speakers and plenary panel participants, including the South African Minister of Health and a representative of the WHO secretary-general, provided important input, as did all the other conference presenters. The LOC depended very heavily on, and was privileged to work with, the IMIA Medinfo Steering Committee, the IMIA Board and the IMIA Executive Director (now the CEO), the advisory committee of friends of SAHIA of long standing, and of course, the SPC and the EC, in the preparation for Medinfo 2010. The commit- 
ted sponsors and donors were essential to the success of the event.

As the SAHIA LOC, we were privileged to have the input of a small core of dedicated SAHIA members, supported by an excellent professional conference secretariat, to ensure that Medinfo participants were able to experience the event in the best possible way for each of them. It was highly fitting that a stalwart of SAHIA, HELINA and IMIA and a member of the LOC, our colleague and friend Dr Sedick Isaacs, was made a fellow of IMIA during Medinfo 2010. On the other hand, we were very saddened by the death of one member of the LOC, Dr Shaheen Khotu, prior to Medinfo, and are still keenly feeling the loss of $\mathrm{Mr}$ Roy Alger a few months after Medinfo 2010. Roy was the driving force behind the two SAHIA bids to host Medinfo, a previous SAHIA president, and a core member of the Medinfo 2010 LOC. This report is dedicated to his memory.

In reviewing Medinfo 2010, it is reasonably safe to say that Medinfo will never be the same, and should not be the same, after the experiences of Medinfo in Africa. As SAHIA, we were forced by both circumstance and design to change the way in which Medinfo was prepared and presented, and we hope that at least some of our experiences will provide a good model for the future. For IMIA, the changing environment, including the IMIA response in the form of a two-year Medinfo cycle after 2013, will necessitate even further changes to ensure the future success of Medinfo conference as a flagship activity of an everevolving IMIA.

Highlights from the conference as reflected in the conference Daily News:

- In opening Medinfo 2010, the South African Minister of Health, Dr Aaron Motsoaledi, announced steps being taken in South Africa to strengthen health information systems to improve the health status of the entire population. He challenged delegates to "reflect



Medinfo 2011 Keynote Speaker Professor Marion Ball, speaking on how we need to think out of the box in her address on Medical Informatics - Back to the Future. critically and openly the accessibility, appropriateness, affordability and cost effectiveness of health information systems and information communication technologies" and to apply them in local, less developed and resource constrained settings.

- Dr Najeeb Al-Shorbaji, representing the WHO Director-General, reflected on the conference theme of 'Partnerships for effective ehealth solutions', noting that "Partnerships within countries as ministries of health must work in full alliance and cooperation with ministries of information and communication technologies and ministries of finance. Partnerships between the public and the private sectors represent the way forward to build the information infrastructure in general and the eHealth applications and services in particular. One pillar in the WHO strategy to support national eHealth programmes is to build partnerships among all stakeholders including the government, the private sector, the UN agencies, the media, the non-government organisations and the citizens being in the heart of eHealth activities."

- In her keynote speech to the conference, Prof Marion Ball reflected on lessons which we had failed to learn in the 31 years since the first IMIA working conference on hospital information systems held in Cape Town in 1979. She highlighted the potential of smart point of care solutions, designed to improve decisionmaking by clinicians and thus making it possible to deliver "predictable and optimized health for all citizens of our countries."

\section{References}

1. Safran C, Marin H, Reti S, editors. Proceedings of Medinfo 2010, the $13^{\text {th }}$ World Congress on Medical and Health Informatics, Cape Town, South Africa, 12 - 15 September 2010. Amsterdam: IOS Press; 2010.

2. Lovis C, Ball M, Boyer C, Elkin PL, Ishikawa K, Jaffe C, et al. Hospital and Health Information Systems - Current Perspectives. Yearb Med Inform 2011:73-82.

Photo credit: Anthea Davison / Neko-lime 